\title{
Analysis of the Association Between Vitamin D Deficiency and Other Diagnoses of Patients by Data Mining Techniques
}

\author{
DBuket KAYA ${ }^{1}$, (DAbdullah GÜNAY2, (D) Osman ÖZÜDOĞRU ${ }^{3}$ \\ ${ }^{1}$ Corresponding Author; Dept. of Electronics and Automation, Firat University, Elazı̆g; \\ bkaya@firat.edu.tr; https://orcid.org/0000-0001-9505-181X \\ ${ }^{2}$ Dept. of Call Center Services, Siirt University, Siirt; \\ abdullah.gunay@siirt.edu.tr; https://orcid.org/0000-0002-5006-1448 \\ ${ }^{3}$ Dept. Of Internal Diseases, Siirt State Hospital, Siirt; \\ osmanozudogru2@gmail.com; https://orcid.org/0000-0003-1212-2251
}

Received 20 January 2020; Revised 14 April 2020; Accepted 23 April 2020; Published online 30 April 2020

\begin{abstract}
One of the most common disorders is vitamin D deficiency. Vitamin D deficiency in individuals with a vitamin D level of less than $20 \mathrm{ng} / \mathrm{ml}$ has been studied in previous studies, which is also associated with other diagnoses. The aim of this study was to investigate the association of vitamin D deficiency patients with other diagnoses. In this respect, a data set consisting of patients whose vitamin d levels have been measured in a public hospital for the last 3 years has been provided. Using this data set, the association rule analysis of data mining techniques was performed. Apriori algorithm was preferred in the analysis. As a result of the analysis, 22 association rules were determined and interpreted.
\end{abstract}

Keywords: Vitamin D Deficiency, Data Mining, Association Rule, Apriori Algorithm

\section{Vitamini Eksikliği ile Hastaların Diğer Tanıları Arasındaki İlişsinin Veri Madenciliği Teknikleriyle Analizi}

$\ddot{O} \mathbf{z}$

Günümüzde en sık görülen rahatsızlıklardan bir tanesi D vitamini eksikliğidir. D vitamini seviyesi 20 ng/ml' den düşük olan bireylerde konulan D vitamini eksikliği rahatsızlığı diğer teşhislerle de ilişkili olduğu geçmiş çalışmalarda incelenmiştir. Çalışmanın amacı D vitamini eksikliği olan hastaların diğer teşhislerle birlikteliğini araştırmaktır. Bu doğrultuda bir devlet hastanesinde son 3 yılın d vitamini düzeyi ölçümü yapılan hastalardan oluşan veri seti temin edilmiştir. Bu veri seti kullanılarak veri madenciliği tekniklerinden birliktelik kuralı analizi yapılmıştır. Yapılan analizde ise Apriori algoritması tercih edilmiştir. Analiz sonucunda 22 adet adet birliktelik kuralı tespit edilmiş ve yorumlanmıştır.

Anahtar Kelimeler: D Vitamini Eksikliği, Veri Madenciliği, Birliktelik Kuralı, Apriori Algoritması

\section{Giriş}

D vitamini eksikliği yaygın görülen rahatsızlıklardan bir tanesidir. D vitamini, kalsiyum homeostazı, kemik sağlığı, düşme ve kırıkları önlemek için yağda çözünen temel bir vitamindir ve diğerlerinin yanı sıra hipertansiyon, diyabet, metabolik sendrom, kanser, otoimmün ve bulaşıcı hastalıklar ile de ilişkilendirilmiştir [1]. Bu konuda yapılan çalışmalarda $\mathrm{D}$ vitamini eksikliğinin diğer teşhislerle birlikteliğini destekler niteliktedir. Bunlardan Zhou ve ark., pnömoni rahatsızlığı ile D vitamini eksikliğinin birlikteliğini analiz etmişlerdir [2]. Aypak ve ark., erişkin obez hastalarda D vitamini düzeyinin vücut kitle indeksi ile ilişkisini incelemişlerdir [3]. Özcan ve ark. ise Fibromiyaljili kadın hastalarda vitamin D düzeyleri ve ağrı, depresyon, uyku ile ilişkisini araştırmışlardır [4]. Erol ve ark., çalışmalarında fiziksel tıp ve rehabilitasyon polikliniğine başvuran hastalarda d vitamin düzeyi ile 
lipid profili ilişkisini incelemişleridir [5]. Yener, çalışmasında kas iskelet sistem ağrısı ile D vitaminİ düzeyleri arasındaki ilişkiyi araştırmıştır [6].

$\mathrm{Bu}$ çalışmada ise $\mathrm{D}$ vitamini düzeyi düşük hastaların teşhisleri veri setinden incelenerek veri madenciliği birliktelik kurallarından apriori algoritması kullanılarak $\mathrm{D}$ vitamin düzeyi düşük hastaların diğer teşhislerle birlikteliği araştırılmıştır. Bununla birlikte hastaların yaş ve cinsiyet bilgilerinin de veri setinden alınarak teşhis ve D vitamini düzeyleri arasındaki ilişki olup olmadığı saptanmaya çalışılmıştır.

\section{2. İlgili Çalışmalar}

Veri madenciliği yöntemleri ile ilgili sağlık sektöründe yer alan veri setleri kullanılarak son yıllarda pek çok çalışma yapılmıştır. Bunlardan Alan, çalışmasında hastane servisleri arasında birliktelik kuralı olup olmadığını veri madenciliği tekniği ile araştırmaya çalışmıştır [7]. Tarımer ve Elmas ise, veri madenciliği birliktelik kuralı algoritmalarından Apriori ve Gri algoritmalarını kullanarak kalp krizi geçiren hastaların kan değerlerindeki değişimleri tetikleyen faktörleri tespit etmeye çalışmış elde edilen sonuçlar ile yapılan analizin başarını ölçmüşlerdir [8]. Koyuncugil ve Özgülbaş, çalışmalarında veri madenciliği yöntemlerinin tıp ve sağlık hizmetleri alanında kullanımı ve uygulamalarını araştırmıştır [9]. Sebik ve Bülbül, çalışmalarında teşhisi konulmuş vakaların yer aldığı veri setini kullanarak veri madenciliği yazılımı WEKA'da hangi algoritmanın daha başarılı olabileceğini ölçmüş bu alanda en başarılı algoritma olarak Naive Bayes algoritmasını tespit etmişlerdir [10]. Güllüoğlu, sağlık alanında veri madenciliği tekniklerinin kullanımı ile alakalı bir çalışmanın nasıl olması ile alakalı bir ön çalışma yapmıştır [11]. Jhang ve ark., yaptıkları çalışmada veri madenciliği birliktelik analizlerinden apriori algoritmasını kullanarak bunama teşhisi konulan hastalar ve onların bakım verenler için spesifik bunama alt tiplerine göre özel bakım ihtiyaçları kombinasyonlarını açıklamışlardır [12]. Zhang ve ark., çalışmalarında veri madenciliği teknikleri kullanarak pediatrik katarakt hastalarının postoperatif komplikasyonlarını tahmin etmeye çalışmaışlardır [13]. Yang ve ark., çalışmalarında apriori algoritmasına dayalı ilişkilendirme kuralı analizleri yaparak kolon karsinomunun tedavisinde bileşik kushen enjeksiyonunun kombine ilaç tedavisi arasındaki ilişkiyi doğrulamaya çalışmışlardır [14]. Chen ve ark., çalışmalarında apriori algoritması kullanılarak küçük hücre olmayan akciğer kanserli hastalarda olumsuz olayların farmakoterapi ile ilişkilerini araştırmışlardır [15]. Tang ve ark. ise, çalışmalarında apriori algoritması kullanarak öncelikle cerrahi operasyon (OP) ve ardından diğer tedavilerle tedavi edilen oral skuamöz hücreli karsinom (OSCC) hastalarında 5 yıllık sağkalım ile ilişkili klinikopatolojik faktörlerin katkısını hesaplamışlardır [16].

\section{Veri Seti}

Çalışma kapsamında bir devlet hastanesinde 2017,2018 ve 2019 yıllarında d vitamini düzeyi ölçülen hastaların veri seti temin edilmiştir. Veri setinde toplam 31540 veri bulunmaktadır. Bu verilein 22111 adeti d vitamini düzeyi labratuvar sonuçlarına göre (Referans Aralığı: 20-150) düşük seviyededir. Bireyde D vitamini düzeyini anlamak için 25(OH)D düzeyine bakılmaktadır. Bu düzey $20 \mathrm{ng} / \mathrm{ml}$ ' den düşük ise D vitamini eksikliği, 21 ile 29 arasında ise $D$ vitamini yetersizliği, $30 \mathrm{ng} / \mathrm{ml}$ ile $150 \mathrm{ng} / \mathrm{ml}$ arasında ise D vitamini düzeyi normal, $150 \mathrm{ng} / \mathrm{ml}$ 'den yüksek ise D vitamini düzeyi yüksektir [17].

Dolayısıyla D vitamini değeri 20 ng/ml'den az olan veriler elenmiştir. 22111 verinin 9249'u birden fazla teşhis konmuş hastadan oluşmaktadır. Çalışmada kullanılan 9249 hastanın demografik bilgileri Tablo 1 ve Tablo 2'de gösterilmiştir.

Tablo 1 Hastaların Cinsiyet Bilgileri

\begin{tabular}{|l|l|l|}
\hline Cinsiyet & Frekans (n) & Yüzde (\%) \\
\hline Erkek & 1621 & 18 \\
\hline Kadın & 7629 & 82 \\
\hline
\end{tabular}


Kaya et. al

Tablo 2 Hastaların Yaş Bilgileri

\begin{tabular}{|c|c|c|c|c|c|c|}
\hline $\begin{array}{c}\text { Yaş } \\
\text { Aralı̆̆ }\end{array}$ & Frekans (n) & Yüzde (\%) & $\begin{array}{c}\text { Frekans (n) } \\
\text { Erkek }\end{array}$ & $\begin{array}{c}\text { Yüzde (\%) } \\
\text { Erkek }\end{array}$ & $\begin{array}{c}\text { Frekans (n) } \\
\text { Kadın }\end{array}$ & $\begin{array}{c}\text { Yüzde (\%) } \\
\text { Kadın }\end{array}$ \\
\hline 17 ve altı & 790 & 8,5 & 227 & 2,45 & 563 & 6,08 \\
\hline $18-35$ & 3855 & 41,7 & 493 & 5,33 & 3362 & 36,35 \\
\hline $36-53$ & 2535 & 27,4 & 415 & 4,49 & 2120 & 22,92 \\
\hline $54-70$ & 1493 & 16,1 & 331 & 3,58 & 1162 & 12,56 \\
\hline $71-88$ & 544 & 5,9 & 149 & 1,61 & 395 & 4,27 \\
\hline 89 ve üstü & 33 & 0,4 & 6 & 0,06 & 27 & 0,29 \\
\hline
\end{tabular}

Çalışmada kullanılan veri setinde yer alan hastaların cinsiyetlerine bakıldığında hastaların \%82'si kadın \%18'i ise erkektir. Hastaların yaş aralıkları ise \%8,5'i 17 yaş ve altı, \%41,7'si 18 ile 35 aralığında, 27,4'ü 36-53 aralığında 16,1'i 54-70 aralığında, 5,9'u 71- 88 aralığında, 0,4'ü ise 89 ve üstü olduğu tespit edilmiştir. Aynı zamanda konulan teşhişler incelendiğinde veri setinde 512 adet farklı teşhis olduğu saptanmıştır. Bu teşhisler tek tek incelenerek 25 gruba ayrılmıştır.

Tablo 3 Teşhis Grupları

\begin{tabular}{|c|c|c|}
\hline Sıra No & Teșhis Adı & Sayı \\
\hline 1 & Solunum_Yolu_Enfeksiyonları & 1145 \\
\hline 2 & Cilt_Hastaliklari & 378 \\
\hline 3 & Diyabet & 1032 \\
\hline 4 & Hipertansiyon & 672 \\
\hline 5 & Psikiyatrik Hastaliklar & 101 \\
\hline 6 & Alzheimer & 2 \\
\hline 7 & Koah-Astim & 300 \\
\hline 8 & Eklem_Agrilari & 407 \\
\hline 9 & Romatizmal_Hastalıklar & 52 \\
\hline 10 & Sindirim_Sist_Hastalıkları & 2624 \\
\hline 11 & Dikkat_Eks_Otizm & 8 \\
\hline 12 & Anemiler & 2866 \\
\hline 13 & Kanser & 38 \\
\hline 14 & Miyalji & 2347 \\
\hline 15 & Hormon_Bozukluğu & 1303 \\
\hline 16 & Vitamin_Eksikliği & 5841 \\
\hline 17 & Uriner_Sist_Hastalıkları & 714 \\
\hline 18 & Yumusak_Doku_Travması & 208 \\
\hline 19 & Metabolik_Kemik_Hastalıkları & 156 \\
\hline 20 & Kalp_Hastalıkları & 334 \\
\hline 21 & Gut & 8 \\
\hline 22 & Beslenme_Bozuklukları & 223 \\
\hline 23 & Nöroloji & 739 \\
\hline 24 & Brusella & 22 \\
\hline 25 & Gebelik & 25 \\
\hline
\end{tabular}


Kaya et. al

\section{4. Çalışmanın Metodolojisi}

Çalışmanın konusu olan D vitamini eksikliği olan hastalara hangi teşhislerin birlikte konduğunun analiz edilmesi amacıyla veri madenciliğiyle elde edilen verilerin birliktelik kuralı yöntemi uygulanması planlanmıştır.

\subsection{Veri Madenciliği}

Genel ifade ile veritabanında bilgi keşfi olarak tanımlanan veri madenciliği kavramı veri ambarlarında depolanmış olan büyük ölçekli veri yığını içerisinden önceden bilinmeyen ve değerli olan bir bilgiyi elde etmeyi amaçlamaktadır [18].

Veri madenciliği süreci bir düze işlemden meydana gelmektedir. Bunlar sırasıyla

I. Veri Toplama

II. Veri Temizleme ve Dönüştürme

III. Model Kurma

IV. Model Değerlendirme

V. Raporlama

VI. Değerlendirme (Scoring)

VII. Uygulama Entegrasyonu

VIII. Model Yönetimi [19] olmak üzere 8 aşamadır.

İlk aşamada ilgili kuruluşların veritabanlarından analizi yapılacak veriler çekilirler. Daha sonraki aşama verileri temizleme ve dönüştürme aşamasıdır. Bu aşamada veriler analiz edilmeye uygun hale getirilmektedir (normalizasyon, dönüştürme, boyut indirgeme vb.). Daha sonra model kurma aşamasında ise kullanılacak algoritma çalışmanın amacına uygun olacak şekilde belirlenir. Model değerlendirme aşamasında da kullanılan algoritmalar çalıştırıldıktan sonra elde edilen algoritmanın uygunluğu değerlendirilir. Raporlama aşamasında elde edilen bulgular veri madenciliği araçları vasıtasıyla raporlanır. Değerlendirme aşamasında ise veri üzerinde veri madenciliği uygulandıktan sonra alınan sonuçlar yorumlanır ve çalışmanın doğru sonuca ulaşıp ulaşmadığı araştırılır. Aynı zamanda farklı metodlar uygulanmışsa onların karşılaştırması yapılır. Daha sonra entegrasyon aşamasında kurulan veri madenciliği modeli gerçek zamanlı olarak çalıştırılmmak amacıyla uygulama içerisine gömülür. Son aşamada ise modelin veriler değiştikçe güncellenmesine gerek olup olmadığ1 denetlenir.

Veri madenciliğinde veri tabanlarından bilgi keşfi için sınıflandırma, kümeleme, regresyon, yapay zeka, yapay sinir ağları, birlik kuralları, karar ağaçları, genetik algoritma, en yakın komşu yöntemi vb. gibi çeşitli algoritmalar ve teknikler kullanılmaktadır [20]. Bu teknik ve algoritmalar günümüzde bankacılık, pazarlama, sigortacılık ve sağlık gibi birçok alanda uygulanmaktadır. Bu çalışmada ise birliktelik kuralı algoritmalarından apriori algoritması tercih edilmştir.

\subsection{Birliktelik Kuralı}

Veri madenciliğinin en önemli tekniklerinden biri olan birliktelik kuralı madenciliği veritabanlarındaki veya diğer veri havuzlarındaki öğeler kümesi arasında ilginç korelasyonlar, sık kalıplar, ilişkilendirmeler veya geçici yapılar çıkarmayı amaçlamaktadır. Birliktelik kuralları teekomünikasyon ağları, pazar ve risk yönetimi, envanter kontrolü gibi çeşitli alanlarda yaygın olarak kullanılmaktadır [21]. Birliktelik ve korelasyon genellikle büyük veri kümeleri arasında sık sık madde seti bulguları bulmaktır. $\mathrm{Bu}$ tür bir bulgu, işletmelerin katalog tasarımı, çapraz pazarlama ve müşteri alışveriş davranış analizi gibi belirli kararları almalarına yardımcı olur. Birliktelik kuralı algoritmalarının, birden fazla güven değeri olan kurallar oluşturabilmesi gerekir. Bununla birlikte, belirli bir veri kümesi için olası birliktelik kuralları sayısı genellikle çok fazladır [20]. 
Kaya et. al

Birliktelik Kuralları, belli bir destek (Support) değerinin üstündeki öğeleri bulur ve bundan sonra kalan öğeler arasından belli bir güven (Confidence) üstündeki ait istenilen kuralları üretir. Lift kuralı ile X ve Y'nin istatiksel olarak bağımsız olması durumda ne kadar birlikte geçtiklerini bulunur [22].

$$
\begin{aligned}
& \text { Destek (Support) }=\frac{\operatorname{frq}(X, Y)}{N} \\
& \text { Güven }(\text { Confidence })=\frac{\operatorname{frq}(X, Y)}{f r q(X)} \\
& \text { Lift }=\frac{\text { Support }}{\operatorname{Support}(X) x \operatorname{Support}(Y)}
\end{aligned}
$$

\subsection{Apriori Algoritması}

Agrawal ve Srikant [22] tarafindan sunulan Apriori algoritması, Kullanıcı tanımlı minimum desteğe göre sık öğe kümeleri bulmaktadır. Algoritmanın ilk geçişinde, aday 1 öğe kümesini oluşturur. Algoritma daha sonra, destek değerleri minimum destekten düşükse, bazı aday 1 öğe kümelerini budayarak sık 1 öğe kümeleri oluşturur. Algoritma, tüm sık rastlanan 1 öğe kümelerini bulduktan sonra, sık 2 öğe kümesini oluşturmak için aday 2 öğe kümeden bazı sık olmayan öğe kümelerini budamak için sık 1 öğeyi birleştirir. Bu işlem, daha fazla aday öğe kümesi oluşturulamayana kadar tekrarlanır [24].

Şekil 1 Apriori Algoritması [25]

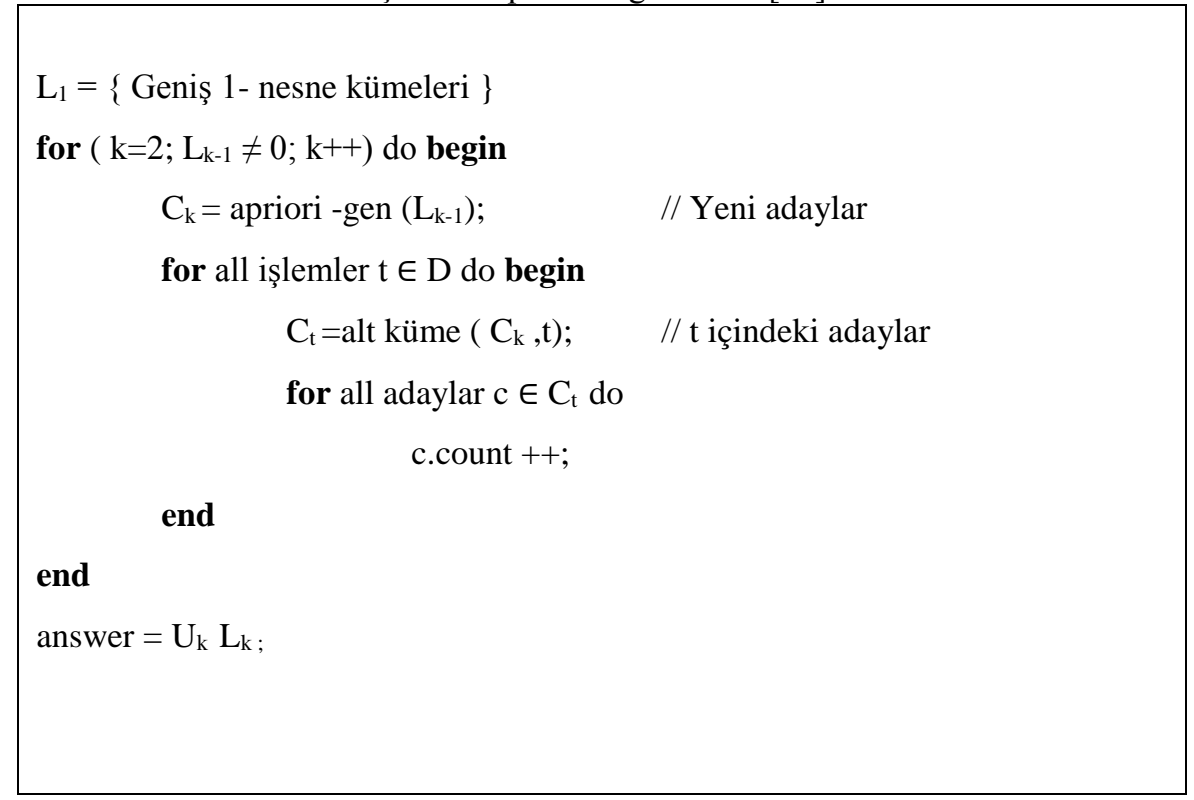

\section{Bulgular}

Çalışmada açık kaynak kod özelliğine sahip Weka programının 3.8.3 sürümü kullanılmıştır. Veriler Weka programında yer alan Apriori algoritmasıyla $\% 80$ ve üzeri güven seviyesi belirlenerek 22 kural oluşturulmuştur. Kurallar Tablo 4'de verilmiştir. 
Kaya et. al

Tablo 4 Birliktelik Kuralları

\begin{tabular}{|c|c|c|c|}
\hline $\begin{array}{l}\text { Sira } \\
\text { No. }\end{array}$ & Birliktelik Kuralı & Conf. & Lift \\
\hline 1 & $\begin{array}{l}\text { YAS='(18-35]' anemiler=T vitamin_eks=T } 1226==>\text { CINSIYET=Kadin } \\
1199\end{array}$ & 0.98 & 1.19 \\
\hline 2 & YAS='(18-35]' anemiler=T $1567==>$ CINSIYET=Kadin 1527 & 0.97 & 1.18 \\
\hline 3 & Anemiler=T vitamin_eks=T $2162==>$ CINSIYET=Kadin 205 & 0.95 & 1.15 \\
\hline 4 & Anemiler=T $2866==>$ CINSIYET=Kadin 2699 & 0.94 & 1.14 \\
\hline 5 & Vitamin_eks=T SONUC='(6.48-9.18]' $1162==>$ CINSIYET=Kadin 1050 & 0.9 & 1.1 \\
\hline 6 & Sindirim_sist_hast=T vitamin_eks=T $1387==>$ CINSIYET=Kadin 1248 & 0.9 & 1.09 \\
\hline 7 & SONUC='(-inf-6.48]' $1115==>$ CINSIYET=Kadin 1000 & 0.9 & 1.09 \\
\hline 8 & YAS='(18-35]' sindirim_sist_hast=T $1056==>$ CINSIYET=Kadin 940 & 0.89 & 1.08 \\
\hline 9 & YAS='(18-35]' vitamin_eks=T $2845==>$ CINSIYET=Kadin 2528 & 0.89 & 1.08 \\
\hline 10 & YAS='(18-35]' 3855 ==> CINSIYET=Kadin 3362 & 0.87 & 1.06 \\
\hline 11 & SONUC='(6.48-9.18]' 1813 ==> CINSIYET=Kadin 1577 & 0.87 & 1.05 \\
\hline 12 & hormon_bozuk=T 1303 ==> CINSIYET=Kadin 1128 & 0.87 & 1.05 \\
\hline 13 & YAS='(36-53]' vitamin_eks=T $1527==>$ CINSIYET=Kadin 1321 & 0.87 & 1.05 \\
\hline 14 & Vitamin_eks=T SONUC='(9.18-11.88]' 1293 ==> CINSIYET=Kadin 1111 & 0.86 & 1.04 \\
\hline 15 & Vitamin_eks=T $5841==>$ CINSIYET=Kadin 4990 & 0.85 & 1.04 \\
\hline 16 & Miyalji=T vitamin_eks=T $1237==>$ CINSIYET=Kadin 1053 & 0.85 & 1.03 \\
\hline 17 & Vitamin_eks=T SONUC='(11.88-14.58]' $1151==>$ CINSIYET=Kadin 975 & 0.85 & 1.03 \\
\hline 18 & Sindirim_sist_hast=T $2624==>$ CINSIYET=Kadin 2205 & 0.84 & 1.02 \\
\hline 19 & YAS='(36-53]' $2535==>$ CINSIYET=Kadin 2120 & 0.84 & 1.01 \\
\hline 20 & SONUC='(9.18-11.88]' $1968==>$ CINSIYET=Kadin 1630 & 0.83 & 1 \\
\hline 21 & Miyalji=T 2347 ==> CINSIYET=Kadin 1923 & 0.82 & 0.99 \\
\hline 22 & SONUC='(11.88-14.58]' $1812==>$ CINSIYET=Kadin 1468 & 0.81 & 0.98 \\
\hline
\end{tabular}

\%98 güven seviyesine sahip ilk kuralda, yaşları 18 ile 35 arasında olup anemi ve vitamin eksikliği teşhisi konulmuş 1199 kadın hasta D vitamini eksikliği gözlemlenmiştir. İkinci kuralda ise D vitamini eksikliğine sahip ve yaşları 18 ile 35 arasında olan 1527 anemi teşhisi konulan hastaların 1527 si yani \%97'si kadındır. Üçüncü kuralda vitamin eksikliği ve anemi teşhisi konmuş D vitamini eksikliği olan hastaların \%95'i kadındır. \%94 güven seviyesine sahip dördüncü kuralda ise D vitamini eksikliğine sahip anemi teşhisi konulan 2866 hastanın 2699'u kadındır. Beşinci kuralda; D vitamini eksikliği olup D vitamini değerleri 6.48 ile 9.18 aralığında olan ve vitamin eksikliği teşhisi konmuş 1162 hastanın 1050'si kadın hastadır. Altıncı kuralda \%90 güven seviyesinde D vitamini eksikliği olan kadın hastalara aynı zamanda sindirim sistem hastalıkları ve vitamin eksikliği teşhisi konmuştur. Yedinci kuralda ise D vitamini düzeyi $6.48^{\prime}$ den düşük 1115 hastanın 1000 'i kadın hasta olduğu gözükmektedir. Yüzde 89 güven seviyesine sahip sekizinci kuralda yaş1 18 ile 35 arasında olan sindirim sistemi hastalıkları teşhisi konmuş kadın hastalarda $\mathrm{D}$ vitamini eksikliği gözükmektedir. 
Dokuzuncu kuralda ise yaşları 18 ile 35 arasında olan vitamin eksikliği teşhisi konmuş 2528 kadın hastanın D vitamini düzeyinin referans aralığının altında olduğu tespit edilmiştir. Güven seviyesi yüzde 87 olan onuncu kuralda yaşları 18 ile 35 arasında olan kadın hastalarda D vitamnini eksikliği gözlemlenmektedir. Güven seviyesi \%87 ile \%81 güven seviyesine sahip diğer 18 kuralda benzer birlikteliklere sahiptir.

\section{Sonuç ve Öneriler}

D vitamini (25-hidroksivitamin D veya 25OHD), çeşitli hastalıkların patogenezinde anahtar bir role sahiptir. D vitamini eksikliği, yaygın bir küresel halk sağlığı sorunudur. D vitamini eksikliği ile ilişkili hastalıkların tespiti de bu konuda önem taşımaktadır.

Teşhislerin birlikteliklerini analiz edebilmek için veri madenciliği yöntemlerşnden birliktelik kuralına başvurmak gerekmektedir. Olayların birlikte gerçekleşme durumlarını çözümleyen veri madenciliği yöntemlerinden Birliktelik Kuralı farklı algoritmalara sahiptir.

Çalışmada D vitamini eksikliğinin diğer hastalıklarla birlikte teşhis edilip edilmediği, birliktelik kuralı yöntemlerinden apriori algoritması kullanılarak analiz edilmiştir. Analiz sonucunda elde edilen kurallar bazı hastalık teşhislerinin belirli bir yaş aralığının ve cinsiyetin birlikteliği tespit edilmiştir. Bu kurallardan en yüksek güven seviyesine (0.98) sahip birinci kuralda yaşları 18 ile 35 arasında değiş̧en D vitamini eksikliği olan kadın 1199 hastaya anemi ve vitamin eksikliği teşhisleri konulmuştur. Aynı şekilde diğer kurallarda benzer niteliktedir.

$\mathrm{Bu}$ çalışmada yapılan analizler sonucunda çalışmanın, ileride yapılacak D vitamini eksikliğinin diğer hastalıklarla ilişkisi konusunda yapılan çalışmalara katkı sağlaması düşünülmektedir.

\section{Referanslar}

[1] C. Palacios and L. Gonzalez, "Is vitamin D deficiency a major global public health problem?”, The Journal of steroid biochemistry and molecular biology., pp.138-145, 2014.

[2] Y. F. Zhou, B. A. Luo and L. L. Qin, "The association between vitamin D deficiency and community-acquired pneumonia: A meta-analysis of observational studies”, Medicine, vol.98, no.38, pp.1-7, 2019.

[3] C. Aypak, H. Yıkılkan, M. Dicle, Ö. Önder and S. Görpelioğlu, "Erişkin obez hastalarda D vitamini düzeyinin vücut kitle indeksi ile ilişkisi”, Haseki Tıp Bülteni, pp. 95-98, 2013.

[4] D. S. Özcan, Ö. Öken, M. Aras and B. F. Köseoğlu, "Fibromiyaljili kadın hastalarda vitamin D düzeyleri ve ağrı, depresyon, uyku ile ilişkisi”, Türkiye Fiziksel Tip ve Rehabilitasyon Dergisi, vol.60, no.4, pp. 329-334, 2014.

[5] A. M. Erol, C. Çelik, K. Hacığlu, D. İldemir, A. Güner, A. Çelik and S. Solum, "Fiziksel Tıp ve Rehabilitasyon polikliniğine başvuran hastalarda D vitamin düzeyi ile lipid profili ilişkisi”, Ege Tip Dergisi, vol.54, no.4, pp.173-176, 2015.

[6] M. Yener, "Kas iskelet sistem ağrısı ile vitamin D düzeyleri arasındaki ilişkinin araştırılması", SDÜ Tip Fakültesi Dergisi, vol.14, no.4, pp. 7-11, 2007

[7] M. Alan, “Tibbi Veriler Üzerinde Birliktelik Kuralları Madenciliği”, Cumhuriyet Üniversitesi Íktisadi ve İdari Bilimler Dergisi, vol.20, no.1, pp. 410-419, 2019 
[8] İ. Tarımer and F. Elmas, "Determınatıon Of Heart Attack Risk On Patients Data By Data Mining Applications.”, Mugla Journal Of Science And Technology, vol.1, no.1, pp.18-23, 2015.

[9] A. Koyuncugil and N. Özgülbaş, "Veri madenciliği: Tıp ve sağllk hizmetlerinde kullanımı ve uygulamaları”, Bilişim Teknolojileri Dergisi, vol.2, no.2, 2009.

[10] N. Sebik and H. Bülbül, "Veri Madenciliği Modellerinin Akciğer Kanseri Veri Seti Üzerinde Başarılarının İncelenmesi”, Tübav Bilim Dergisi , vol. 11 no.3, pp.1-7, 2018.

[11] S. S. Güllüoglu, "Data Mining Studies in Medical and Healthcare: A Preliminary Study for Cancer Diagnosis”. AJIT-e, vol.2, no.5. 2011.

[12] K. M. Jhang, M. C. Chang, T. Y. Lo, C. W. Lin, W. F. Wang and H. H. Wu, "Using the apriori algorithm to classify the care needs of patients with different types of dementia", Patient preference and adherence, pp.1899-1912, 2019.

[13] K. Zhang, X. Liu, J. iang, W. Li, S. Wang, L. Liu and L. Wang, "Prediction of postoperative complications of pediatric cataract patients using data mining.", Journal of translational medicine, vol.17, no.1, pp.2-10, 2019.

[14] H. Yang, Y. Xie, J. Ni, Y. Liu, R. Song, C. Chen and Y. Zhang, “Association Rule Analysis for Validating Interrelationships of Combined Medication of Compound Kushen Injection in Treating Colon Carcinoma: A Hospital Information System-Based Real-World Study.”, Evidence-Based Complementary and Alternative Medicine, 2018.

[15] W. Chen, J. Yang, H. L. Wang, Y. F. Shi, H. Tang and G. H. Li, "Discovering Associations of Adverse Events with Pharmacotherapy in Patients with Non-Small Cell Lung Cancer Using Modified Apriori Algorithm”, BioMed Research International, 2018.

[16] J. Y. Tang, L. Y. Chuang, E. Hsi, Y. D. Lin, C. H. Yang and H. W. Chang, "Identifying the association rules between clinicopathologic factors and higher survival performance in operation-centric oral cancer patients using the apriori algorithm”, BioMed Research International, 2013.

[17] M. F. Holick, "Vitamin D Deficiency Medical Progress", The New England Journal Of Medicine, vol. 357, no. 3, pp. 266-281, 2007.

[18] G. Dondurmacı and A. Çınar, "Yönetim Bilişim Sistemleri”, İstanbul: Papatya Yayıncılık, 2014.

[19] A. Tekerek, "Veri madenciliği süreçleri ve açık kaynak kodlu veri madenciliği araçları", XIII. Akademik Bilişim Konferansı, pp.161-169, 2011.

[20] M. Bharati and M. Ramageri, "Data mining techniques and applications.”, Indian Journal of Computer Science and Engineering, vol. 1 no. 4, pp.301-305, 2010.

[21] S. Kotsiantis and D. Kanellopoulos, “Association rules mining: A recent overview”, GESTS International Transactions on Computer Science and Engineering, vol.32, no.1, pp.71-82, 2006. 
Kaya et. al

[22] “Association Rules (Birliktelik Kuralları)", [Online] Available:

https://erdincuzun.com/makine_ogrenmesi/association-rules-birliktelik-kurallari/, [Accessed : 25-Dec-2019].

[23] R. Agrawal and R. Srikant, "Fast Algorithms for Mining Association Rules”, Proceedings of the 20th International Conference on Very Large Data Bases, pp. 487-499, 1994.

[24] Y. Ye and C. C. Chiang, “A parallel apriori algorithm for frequent itemsets mining.”, Fourth International Conference on Software Engineering Research, Management and Applications (SERA'06) IEEE., pp. 87-94., 2006.

[25] G. Silahtaroğlu, Veri madenciliği Kavram ve Algoritmaları, İstanbul:Papatya Yayınları, 2016. 